\title{
Dlx-2 is implicated in TGF- $\beta$ - and Wnt-induced epithelial-mesenchymal, glycolytic switch, and mitochondrial repression by Snail activation
}

\author{
SU YEON LEE ${ }^{1}$, HYUN MIN JEON ${ }^{1}$, MIN KYUNG JU ${ }^{1}$, EUI KYONG JEONG ${ }^{1}$, CHO HEE KIM ${ }^{1,4}$, \\ MI-AE YOO ${ }^{1}$, HYE GYEONG PARK ${ }^{2}$, SONG IY HAN ${ }^{3}$ and HO SUNG KANG ${ }^{1}$ \\ ${ }^{1}$ Department of Molecular Biology, College of Natural Sciences, ${ }^{2}$ Nanobiotechnology Center, \\ Pusan National University, Pusan 609-735; ${ }^{3}$ The Division of Natural Medical Sciences, \\ College of Health Science, Chosun University, Gwangju 501-759, Republic of Korea
}

Received November 17, 2014; Accepted January 5, 2015

DOI: 10.3892/ijo.2015.2874

\begin{abstract}
Epithelial-mesenchymal transition (EMT) and oncogenic metabolism (including glycolytic switch) are important for tumor development and progression. Here, we show that Dlx-2, one of distal-less (Dlx) homeobox genes, induces EMT and glycolytic switch by activation of Snail. In addition, it was induced by TGF- $\beta$ and Wnt and regulates TGF- $\beta$ - and Wnt-induced EMT and glycolytic switch by activating Snail. We also found that TGF- $\beta /$ Wnt suppressed cytochrome $c$ oxidase (COX), the terminal enzyme of the mitochondrial respiratory chain, in a Dlx-2/Snail-dependent manner. TGF- $\beta /$ Wnt appeared to downregulate the expression of various COX subunits including COXVIc, COXVIIa and COXVIIc; among these COX subunits, COXVIc was a common target of TGF- $\beta$, Wnt, Dlx-2 and Snail, indicating that COXVIc downregulation plays an important role(s) in TGF- $\beta$ / Wnt-induced COX inhibition. Taken together, our results showed that Dlx- 2 is involved in TGF- $\beta$ - and Wnt-induced EMT, glycolytic switch, and mitochondrial repression by Snail activation.
\end{abstract}

\section{Introduction}

Epithelial-mesenchymal transition (EMT) is an essential process for tumor invasion and metastasis (1-5). EMT is the conversion of epithelial cells into more invasive mesenchymal cells and characterized by a loss of cell-cell contact and

Correspondence to: Dr Ho Sung Kang, Department of Molecular Biology, College of Natural Sciences, Pusan National University, Pusan 609-735, Republic of Korea

E-mail: hspkang@pusan.ac.kr

Present address: ${ }^{4}$ DNA Identification Center, National Forensic Service, Seoul 158-707, Republic of Korea

Key words: Dlx-2, Snail, epithelial-mesenchymal transition, glycolytic switch, COXVIc apical-basal polarity through repression of the expression of E-cadherin and other epithelial markers and activation of the expression of mesenchymal markers (such as vimentin and fibronectin). TGF- $\beta$ and Wnt are known to induce EMT during cancer development and progression (1-3,5-8). The transcription factor Snail is implicated in the repression of E-cadherin expression in response to TGF- $\beta$ and Wnt. We previously showed that Wnt/Snail signaling induces the Warburg effect (also termed as glycolytic switch) (9). The Warburg effect is that cancer cells mainly use glycolysis for ATP production instead of mitochondrial oxidative phosphorylation, even in the presence of oxygen. The glycolytic switch increases the availability of biosynthetic precursors for nucleotides, lipids and amino acids needed for tumor cell proliferation (10-14). Mitochondrial dysfunction is closely linked to the induction of glycolytic switch (15-18). In cancer cells, inhibition of the glycolytic switch results in growth failure; thus, molecules implicated in glycolytic switch are regarded as potential target for cancer therapies.

Dlx-2 is one of the human distal-less (Dlx) gene family proteins that play an important role(s) in the embryonic development $(19,20)$. Increased Dlx-2 expression is observed in a number of tumor tissues, suggesting an essential role of Dlx-2 in carcinogenesis (21-23). Recently, Dlx-2 was shown to be induced by TGF- $\beta$ and involved in the shift of the TGF- $\beta$ tumor suppressive activity to its tumor promoting activity (23). Inhibition of Dlx-2 expression has been shown to impair the metastasis ability of B16 melanoma cells (23). In addition, we previously showed that Dlx-2 is induced by reactive oxygen species (ROS) and is implicated in metabolic stress-induced necrosis (21). ROS contribute to cancer development and progression $(24,25)$. However, the precise mechanism of Dlx-2 in tumor progression remains to be elucidated.

In this study, we show that Dlx-2 is implicated in TGF- $\beta$ - and Wnt-induced EMT and glycolytic switch via Snail induction. We also show that TGF- $\beta /$ Wnt suppressed mitochondrial respiration through inhibiting cytochrome $c$ oxidase $(\mathrm{COX})$, the terminal enzyme of the mitochondrial respiratory chain, by Dlx-2/Snail cascade. COXVIc appeared to be a common target of Dlx-2, Snail, TGF- $\beta$ and Wnt. Taken 
together, our results show that Dlx-2 plays an important role in TGF- $\beta$ /Wnt-induced EMT, glycolytic switch and mitochondrial repression and COX inhibition.

\section{Materials and methods}

Cell culture. MCF-7, Madin Darby Canine Kidney (MDCK) and L cells were obtained from the American Type Culture Collection (ATCC; authenticated by short tandem repeat profiling). Wnt3a-secreting L cells and HCT116 cells were provided by Dr D.S. Min and Dr Y.J. Kim, respectively (Pusan National University, Pusan, Korea). The cell lines were passaged two times per week and low-passage cultures (passages 5-25) were used for the experiments. The cells were routinely tested negative for mycoplasma using the Mycoplasma PCR Detection kit (iNtRON Biotechnology). MCF-7 and MDCK cells were cultured in Eagle's minimal essential medium (EMEM; Hyclone, Logan, UT, USA); and L cells and Wnt3a secreting L cells in Dulbecco's modified Eagle's medium (DMEM; Hyclone); HCT116 cells were cultured RPMI supplemented with $10 \%(\mathrm{v} / \mathrm{v})$ heat-inactivated fetal bovine serum (FBS, Hyclone) and $1 \%$ penicillin-streptomycin (PS, Hyclone) in a $37^{\circ} \mathrm{C}$ humidified incubator with $5 \% \mathrm{CO}_{2}$. Recombinant TGF- $\beta$ (R\&D Systems, MN, USA) was applied to cells at a concentration of $10 \mathrm{ng} / \mathrm{ml}$.

Transfection and short hairpin RNA (shRNA) interference. The expression vectors pCAGGS-Dlx-2 (provided by Dr John L.R. Rubenstein, University of California at San Francisco) and pCR3.1-Snail-Flg (provided by J.I. Yook, Yonsei University, Korea) were transfected into MCF-7 cells using jetPEI (Polyplus transfection). pSUPER vectors for shRNA against control, Dlx-2, Snail, Smad2, Smad3, Smad4, $\beta$-catenin, TCF4, Axin1, Axin2 and COXVIc (abbreviations; shCon, shDlx-2, etc.) were produced and transfected as described previously (9).

Immunoblotting and quantitative real-time PCR ( $q R T-P C R)$. Immunoblotting and qRT-PCR were performed as described previously $(9,26)$. Immunoblotting was performed with the following antibodies: Dlx-2 (Millipore, Billerca, MA, USA); Snail (Abgent, San Diego, CA, USA); E-cadherin, vimentin, COXVIIc and COX19 (Santa Cruz, CA, USA); COXVIc, COXVIIa, and COXVIIb (Mitoscience, Eugene, OR, USA); SCO2 and COX18 (Abcam, Cambridge, MA, UK); $\alpha$-tubulin (Biogenex, CA, USA). Total mRNA was isolated from cells by using the TRIzol (Invitrogen, Carlsbad, CA, USA) according to the supplier's instructions. Transcript levels were assessed with qRT-PCR with primers for Dlx-2, Snail, E-cadherin and $\beta$-actin. Values are normalized to $\beta$-actin.

Immunofluorescence (IF) microscopy. MCF-7 cells were fixed for $10 \mathrm{~min}$ in $3.7 \%$ formaldehyde in PBS, permeabilized in PBS containing $0.2 \%$ Triton X-100 for $30 \mathrm{~min}$, and blocked with $2 \%$ BSA in $0.1 \%$ PBST for 3 h. For E-cadherin staining, cells were incubated with mouse anti-E-cadherin (Santa Cruz) antibody for overnight at $4^{\circ} \mathrm{C}$ and immunostained with Alexa-Fluoro-488-labeled anti-mouse secondary antibody (Molecular Probes, NY, USA). Hoechst 33342 (Molecular Probes) was used to stain cell nuclei.
Table I. shRNA target sequences used in this study.

Gene Target sequence $5^{\prime} \rightarrow 3^{\prime}$

$\begin{array}{ll}\text { Control shRNA } & \text { AATTCTCCGAACGTGTCACGT } \\ \text { Snail shRNA } & \text { GCGAGCTGCAGGACTCTAA } \\ \text { Dlx-2 shRNA } & \text { TTCGGATAGTGAACGGGAA } \\ \text { Smad2 shRNA } & \text { AACAAACCAGGTCTCTTGATG } \\ \text { Smad3 shRNA } & \text { CAGCACATAATAACTTGGACCTGCA } \\ \text { Smad4 shRNA } & \text { CGAGTTGTATCACCTGGAA } \\ \beta \text {-catenin shRNA } & \text { GATAAAGGCTACTGTTGGA } \\ \text { Axin1 shRNA } & \text { GCCGACCTTAAATGAAGATGA } \\ \text { Axin2 shRNA } & \text { AGACGATACTGGACGATCA } \\ \text { TCF4 shRNA } & \text { GCCTTTCACTTCCTCCGATTA }\end{array}$

Dlx, distal-less; Axin, axis inhibition protein; TCF, T-cell factor.

Chromatin immunoprecipitation (ChIP) assay. ChIP assays were conducted using a ChIP Assay kit (Millipore). IgG, anti-Dlx-2 or anti-Snail (Santa Cruz) was used to immunoprecipitate DNA-containing complexes. ChIP-enriched DNA was analyzed by PCR using primers complementary to the promoter regions.

Assays for mitochondrial respiration, COX activity, glucose (Glc) consumption, lactate (Lac) production and ATP production. Mitochondrial respiration and COX activity were measured as described previously $(9,27)$. For mitochondrial respiration assay, exponentially growing cells $\left(1.5 \times 10^{6}\right)$ were washed with TD buffer $(137 \mathrm{mM} \mathrm{NaCl}$, $5 \mathrm{mM} \mathrm{KCl}, 0.7 \mathrm{mM} \mathrm{Na} \mathrm{HPO}_{4}, 25 \mathrm{mM}$ Tris-HCl, $\mathrm{pH}$ 7.4), and were collected and resuspended in complete medium without phenol red. The cells $\left(5 \times 10^{5}\right)$ were transferred to the Mitocell chamber equipped with a Clark oxygen electrode (782 Oxygen Meter, Strathkelvin Instruments, Glasgow, UK). Oxygen consumption rates were measured after adding $30 \mu \mathrm{M}$ DNP to obtain maximum respiration rate and its specificity for mitochondrial respiration was confirmed by adding $5 \mathrm{mM} \mathrm{KCN} \mathrm{(29).} \mathrm{COX} \mathrm{activity} \mathrm{was} \mathrm{determined} \mathrm{by}$ measuring the $\mathrm{KCN}$-sensitive $\mathrm{COX}$-dependent $\mathrm{O}_{2}$ consumption rate by adding $3 \mathrm{mM}$ TMPD in the presence of $30 \mu \mathrm{M}$ DNP and $20 \mu \mathrm{M}$ antimycin A. Glc, Lac and intracellular ATP levels were determined using a glucose oxidation assay kit (Sigma, MO, USA), a colorimetric and fluorescencebased lactate assay kit (BioVision, CA, USA), and an ATP Bioluminescence Assay kit (Roche, Switzerland), respectively. The level of ATP produced by aerobic respiration and glycolysis was determined by measuring Lac production and oxygen consumption $(9,28)$.

Human tumor samples. All human tissues from patients \#70331 (infiltrating ductal carcinoma),\#69965 (invasive ductal carcinoma), \#69941 (metaplastic carcinoma) and \#70168 (pleomorphic lobular carcinoma) with breast cancer and normal matched tissue pairs from the same individuals were provided by the National Biobank of Korea, PNUH in compliance with all the regulations related to biomedical research 
Table II. Primers used in this study for qRT-PCR and ChIP assays.

\begin{tabular}{|c|c|c|c|c|}
\hline Primers for qRT-PCR & & & Sequence $5^{\prime} \rightarrow 3^{\prime}$ & Annealing ${ }^{\circ} \mathrm{C}$ \\
\hline \multirow[t]{2}{*}{$\beta$-actin } & NM_001101.3 & Sense & ACTCTTCCAGCCTTCСТTCC & \\
\hline & & Antisense & TGTTGGCGTACAGGTCTTTG & \\
\hline \multirow[t]{2}{*}{ Dlx-2 } & NM_004405 & Sense & GCACATGGGTTCCTACCAGT & 62 \\
\hline & & Antisense & ACTTTCTTTGGCTTCCCGTT & \\
\hline \multirow[t]{2}{*}{ Snail } & NM_005985 & Sense & ATCGGAAGCCTAACTACAGC & 55 \\
\hline & & Antisense & CAGAGTCCCAGATGAGCATT & \\
\hline \multirow[t]{2}{*}{ E-cadherin } & NM_004360 & Sense & GATTTTGAGGCCAAGCAGCA & 55 \\
\hline & & Antisense & AGATGGGGGCTTCATTCACA & \\
\hline \multirow[t]{2}{*}{ COXIV } & NM_001861 & Sense & AACGAGTGGAAGAAGTGAGA & 53 \\
\hline & & Antisense & GTAAATAGGCATGGAGTTGC & \\
\hline \multirow[t]{2}{*}{ COXVa } & NM_004255 & Sense & CCCAAGGATTTATTGACATT & 53 \\
\hline & & Antisense & CCATTACATGGCTTGGTACT & \\
\hline \multirow[t]{2}{*}{$\mathrm{COXVb}$} & NM_001862 & Sense & ACAATGTACTGGCCCCAAAG & 53 \\
\hline & & Antisense & CTTTGTGCAGCCAAAACCAG & \\
\hline \multirow[t]{2}{*}{ COXVIa } & NM_004373 & Sense & ATGTGGAAGACTCTCACCTTC & 60 \\
\hline & & Antisense & GGAAGTGGATTCACATGAGG & \\
\hline \multirow[t]{2}{*}{ COXVIb } & NM_001863 & Sense & CTTCCGGCTGGTAGTAGTTC & 57 \\
\hline & & Antisense & GCCAGCAGTTTCTAGTCTGG & \\
\hline \multirow[t]{2}{*}{ COXVIc } & NM_004374 & Sense & TTAGTCAGGAAGGACGTTGG & 53 \\
\hline & & Antisense & GGATAGCACGAATGCTACAG & \\
\hline \multirow[t]{2}{*}{ COXVIIa } & NR_029466 & Sense & GGTTCAGTTTCATTCAGCTC & 53 \\
\hline & & Antisense & GCTTTATTGGTGGCAGTTAC & \\
\hline \multirow[t]{2}{*}{ COXVIIb } & NM_001866 & Sense & CGCAGTTCTAGCTTCACCTT & 53 \\
\hline & & Antisense & TCAGGTGTACGTTTCTGGTG & \\
\hline \multirow[t]{2}{*}{ COXVIIc } & NM_001867 & Sense & CTGCATTTGCTACACCCTTC & 57 \\
\hline & & Antisense & GTTTGATCCACTTCCAGAGG & \\
\hline \multirow[t]{2}{*}{ COXVIII } & NM_004074 & Sense & TCCCTCACACTGTGACCTGACCAGC & 57 \\
\hline & & Antisense & GGGGACCCCACCAAGCAGGGTCAGT & \\
\hline \multirow[t]{2}{*}{ COX10 } & NM_001303 & Sense & CCTGTCAAGCTTCAAGACCT & 59 \\
\hline & & Antisense & GTCTCGGTTACCAAATACGG & \\
\hline \multirow[t]{2}{*}{ COX11 } & NM_004375.2 & Sense & GAACTTTTGATGTCAGTAAATC & 55 \\
\hline & & Antisense & GGCTATTTTATATTCAGAGTTCT & \\
\hline \multirow[t]{2}{*}{ COX15 } & NM_004376 & Sense & TGTACCATTCTCAGGTGGTG & 53 \\
\hline & & Antisense & CAACCAGCTCTTGCATAAAC & \\
\hline \multirow[t]{2}{*}{ COX17 } & NM_005694 & Sense & GGCATAGATTTGGCTGTCTC & 55 \\
\hline & & Antisense & GGCCTCAATTAGATGTCCAC & \\
\hline \multirow[t]{2}{*}{ COX18 } & NM_173827.2 & Sense & ATCGCTTGAACCTGGAATAC & 59 \\
\hline & & Antisense & AGAGACAGGCACTTTGGTTC & \\
\hline \multirow[t]{2}{*}{ COX19 } & NM_001031617.2 & Sense & GACCATGGGTAACTGAAACC & 59 \\
\hline & & Antisense & ATCCCAGCAATTCTTCACTC & \\
\hline \multirow[t]{2}{*}{ LRPPRC } & NM_133259.3 & Sense & AAGCATGGCAAGCTCCAAGA & 57 \\
\hline & & Antisense & AGCTGCGCCATTTAGCATGT & \\
\hline \multirow[t]{2}{*}{ SURF1 } & NM_003172.2 & Sense & AGAAACCAGGCAGCCTTTTG & 57 \\
\hline & & Antisense & TGCTCTGGAAGTTGGCATCA & \\
\hline SCO1 & NM_004589.2 & Sense & ATGAAGCACGTCAAGAAAGA & 55 \\
\hline & & Antisense & TCCCCAGTATGAGTTGTGAG & \\
\hline $\mathrm{SCO} 2$ & NM_005138 & Sense & CAGCCTGTCTTCATCACTGT & 55 \\
\hline & & Antisense & TAGTCCTGGTCCTCATCCTT & \\
\hline
\end{tabular}


Table II. Continued.

\begin{tabular}{|c|c|c|c|}
\hline Primers for ChIP assays & & Sequence $5^{\prime} \rightarrow 3^{\prime}$ & Annealing ${ }^{\circ} \mathrm{C}$ \\
\hline \multirow[t]{2}{*}{ E-cadherin E4 } & Sense & TCCATTTCTTGGTCTACGCC & 55 \\
\hline & Antisense & CACCTTCAGCCAACCTGTTT & \\
\hline \multirow[t]{2}{*}{ E-cadherin D1 } & Sense & CCTCGGCAACATAGTGAGATCCCC & 60 \\
\hline & Antisense & TCCACCСТCTTCAGCCTCCTG & \\
\hline \multirow[t]{2}{*}{ E-cadherin D2 } & Sense & GGCCAACATGGTGAAACCCCGTCTG & 60 \\
\hline & Antisense & CCGCCTGCCGGGTTCAAGAGAC & \\
\hline \multirow[t]{2}{*}{ E-cadherin D3 } & Sense & GGGCAAGACAGAGCGAGACTCC & 60 \\
\hline & Antisense & ACTCCTGGGCTGAAGCGATCC & \\
\hline \multirow[t]{2}{*}{ Snail D1 } & Sense & GCATGCCCATCCCACCCCATC & 60 \\
\hline & Antisense & GGGTCGGGGTGACTTCCCAGA & \\
\hline \multirow[t]{2}{*}{ Snail D3 } & Sense & TGCCTCGACCACTATGCCGC & 60 \\
\hline & Antisense & CCAGAACCCCTCCAACGCACC & \\
\hline \multirow[t]{2}{*}{ COXVIc E1 } & Sense & САCСАCTTCTTCTCTGGGGGT & 60 \\
\hline & Antisense & ATCAAGGGTCTACCCAGCTGAAAA & \\
\hline \multirow[t]{2}{*}{ COXVIc E2 } & Sense & GAACTTCGGCTGTCACCTGCGG & 60 \\
\hline & Antisense & AGGGACCGGACTCACCTCAACAC & \\
\hline \multirow[t]{2}{*}{ COXVIIa E1 } & Sense & GAGGAGGCTGAGGCACCACGA & 60 \\
\hline & Antisense & CAGTAACGGCCTGGGGCGAGAG & \\
\hline \multirow[t]{2}{*}{ COXVIIb E1 } & Sense & TACGGATCCCGGCTGAAAGCCAT & 60 \\
\hline & Antisense & AGTGCGCTTTTGACCAAGGGAAACA & \\
\hline \multirow[t]{2}{*}{ COXVIIb E2 } & Sense & AGGACATTCTTGGTAGA & 53 \\
\hline & Antisense & AGCTGCATCGATACCATTTGGGTT & \\
\hline \multirow[t]{2}{*}{ COXVIIc E1 } & Sense & ACGTTCATCAGGCGGACACCA & 60 \\
\hline & Antisense & AGGGCAGGGAAAACTCAAGTCTGG & \\
\hline \multirow[t]{2}{*}{ COXVIIc E2 } & Sense & GTGTAAGGGGCACGGCTTCGTT & 60 \\
\hline & Antisense & TCTGGCTATCATCTCCCACGCCA & \\
\hline \multirow[t]{2}{*}{ COXVIIc E3 } & Sense & GCATCCTAGCGCGTAGCCGCT & 60 \\
\hline & Antisense & TCCCGGAGCCATCTCAGGGCTT & \\
\hline \multirow[t]{2}{*}{ COX19 E1 } & Sense & CTCGGTGGTGTCACCTGGCTC & 62 \\
\hline & Antisense & AGACCTCATCACGGGGCCCATC & \\
\hline \multirow[t]{2}{*}{ COX19 E2 } & Sense & AACCGAGGCCCCAGCAGACA & 62 \\
\hline & Antisense & TTGGTGAGAAACCGAGGCCCA & \\
\hline \multirow[t]{2}{*}{ COX19 D1 } & Sense & TGGGCAACAAGAGAGAGACTCCGT & 60 \\
\hline & Antisense & TTGGGTTAGGGGCCGTCCCAAT & \\
\hline \multirow[t]{2}{*}{ COX19 D3 } & Sense & GCCCAGGAGTTAAGGACCAGCCT & 60 \\
\hline & Antisense & GCTGCGACCACAGGCACACA & \\
\hline \multirow{2}{*}{$\begin{array}{l}\text { COXVIIa } \\
\text { (negative control) }\end{array}$} & Sense & GGTTCAGTTTCATTCAGCTC & 53 \\
\hline & Antisense & GCTTTATTGGTGGCAGTTAC & \\
\hline
\end{tabular}

Dlx, distal-less; COX, cytochrome $c$ oxidase; LRPPRC, leucine-rich pentatricopeptide repeat-containing protein; SCO, synthesis of cytochrome $c$ oxidase.

with human samples, including informed consent of the patients for the use of their samples. We performed qRT-PCR and immunoblotting with cancer tissues. TRIzol extraction of total RNA and subsequent extraction of protein was carried out essentially according to the manufacturer's specifications (Invitrogen Corp.). To a 50-100 mg tissue segment, $1 \mathrm{ml}$ of 
Table III. Putative Snail binding site (E-box) and Dlx-2 binding site in the gene promoters.

\begin{tabular}{|c|c|c|c|}
\hline Gene & $\begin{array}{c}\text { Snail } \\
\text { binding } \\
\text { site }\end{array}$ & $\begin{array}{l}\text { Dlx-2 } \\
\text { binding } \\
\text { site }\end{array}$ & $\begin{array}{l}\text { Positions from } \\
\text { transcription } \\
\text { start site }\end{array}$ \\
\hline \multirow[t]{7}{*}{ E-cadherin } & E1 & & ${ }^{-465}$ CACCTG $^{-460}$ \\
\hline & E2 & & -79 CAGGTG $^{-74}$ \\
\hline & E3 & & ${ }^{-28} \mathrm{CACCTG}^{-23}$ \\
\hline & E4 & & ${ }^{+22} \mathrm{CACCTG}^{+27}$ \\
\hline & & D1 & -960 TAAT ${ }^{-957}$ \\
\hline & & D2 & ${ }_{-855}$ ATTA $^{-852}$ \\
\hline & & D3 & -673 ATTA ${ }^{-670}$ \\
\hline \multirow[t]{3}{*}{ Snail } & & D1 & -861 TAAT $^{-858}$ \\
\hline & & $\mathrm{D} 2$ & -749 TAATTA ${ }^{-744}$ \\
\hline & & D3 & ${ }^{+159} \mathrm{TAAT}^{+162}$ \\
\hline \multirow[t]{2}{*}{ COXVIc } & E1 & & ${ }^{-516} \mathrm{CAGCTG}^{-511}$ \\
\hline & E2 & & ${ }^{+282} \mathrm{CACCTG}^{+287}$ \\
\hline COXVIIa & E1 & & ${ }^{+292} \mathrm{CACCTG}^{+297}$ \\
\hline \multirow[t]{2}{*}{ COXVIIb } & E1 & & ${ }^{+55} \mathrm{CAGCTG}^{+60}$ \\
\hline & E2 & & ${ }^{+542} \mathrm{CACCTG}^{+547}$ \\
\hline \multirow[t]{3}{*}{ COXVIIc } & E1 & & ${ }^{-531}$ CAGGTG $^{-526}$ \\
\hline & E2 & & ${ }^{+276} \mathrm{CACCTG}^{+281}$ \\
\hline & E3 & & ${ }^{+447} \mathrm{CACCTG}^{+452}$ \\
\hline \multirow[t]{5}{*}{ COX19 } & E1 & & $-377 \mathrm{CACCTG}^{-372}$ \\
\hline & E2 & & ${ }^{-251} \mathrm{CACCTG}^{-246}$ \\
\hline & & D1 & ${ }^{-959}$ TAATTA ${ }^{-954}$ \\
\hline & & D2 & ${ }^{-858}$ TAAT $^{-855}$ \\
\hline & & D3 & -751 ATTA ${ }^{-748}$ \\
\hline
\end{tabular}

Dlx, distal-less; COX, cytochrome $c$ oxidase.

TRIzol was added, and the sample was homogenized with 2-3 min homogenisation with a tissue lyser (Qiagen, Hilden, Germany) at $30 \mathrm{~Hz}$.

Measurement of circularity. For circularity, microscopic images were analyzed with Axiovision LE software (Release 4.8 version). Circularity was measured with the Axiovision LE software Measure command that calculates object circularity using the formula circularity $=4 \pi\left(\right.$ area $/$ perimeter $\left.{ }^{2}\right)$. Circularity value of 1.0 indicates a perfect circle. As the value approaches 0.0 , it indicates an increasingly elongated polygon.

Statistical analysis. qRT-PCR and assays for mitochondrial respiration, COX activity, Glc consumption, Lac production and ATP production were performed at least in triplicate and most experiments were repeated more than twice. Data were analyzed by the Student's t-test (unpaired, two-tailed) and results were expressed as mean $\pm \mathrm{SE}$. $\mathrm{P}<0.05$ was considered statistically significant.

\section{Results and Discussion}

Dlx-2 induces EMT via Snail activation. We examined the effects of Dlx-2 overexpression in non-invasive breast cancer cell line MCF-7. Dlx-2 overexpression in MCF-7 cells induced the loss of cell polarity and the formation of elongated morphology with pseudopodia, which are a characteristic of mesenchymal cells, indicating that Dlx-2 may induce EMT (Fig. 1A). Spindle quantification also supported Dlx-2-induced EMT (Fig. 1A). The phenotypical change was accompanied by a decreased expression of an epithelial marker E-cadherin, as revealed by IF, qRT-PCR and immunoblotting (Fig. 1A-C). In addition, Dlx-2 increased the levels of a mesenchymal marker vimentin (Fig. 1C).

We examined whether Dlx-2 directly regulates E-cadherin expression. We found three putative Dlx-2 binding sites between $-1,000$ and $+1,000$ from the transcription start site (TSS) in the promoter of E-cadherin. However, Dlx-2 binding to the E-cadherin promoter was not detected in ChIP analysis (Fig. 1D). Thus, we thought that Dlx-2 may indirectly reduce E-cadherin by activating other E-cadherin repressor. Snail is a typical E-cadherin repressor for EMT (2). Therefore, we examined whether Snail is involved in Dlx-2-induced EMT. Dlx-2 overexpression prominently increased Snail protein (Fig. 1E) and mRNA levels (Fig. 1F). Three putative Dlx-2 binding sites were found in the Snail promoter (Fig. 1G). ChIP assay showed Dlx-2 binding to the Snail promoter (Fig. 1G), indicating that Dlx-2 regulates Snail expression. Note that Dlx-2 binding to the Snail promoters was detected only at an early time-point (3 h) after transfection (Fig. 1G). We examined whether Snail is involved in Dlx-2-induced EMT. shSnail (hereafter, shSnail) prevented Dlx-2-induced EMT and E-cadherin downregulation and vimentin upregulation (Fig. 1A-C), indicating that Dlx-2 induces EMT via Snail activation. We performed ChIP assay to examine Snail binding to the E-cadherin promoter. 4 E-boxes for Snail binding are found in human E-cadherin promoter; but Snail has been shown to bind to the E-boxes 1,3 and 4 with the most strong binding activity for E-box $4(6,29)$. Dlx-2 and Snail overexpression enhanced Snail binding to the E-box 4 of the E-cadherin promoter (Fig. $1 \mathrm{H}$ ), indicating that Dlx-2-induced Snail can interact with E-box sites (including E-box 4) in the E-cadherin promoter to repress E-cadherin expression.

Dlx-2/Snail cascade is implicated in TGF- $\beta$ - and Wnt3ainduced EMT. TGF- $\beta$ and Wnt signaling pathways are known to induce EMT through Snail activation $(2,3,8)$. Thus, we examined if the Dlx-2/Snail cascade is involved in TGF- $\beta$ and Wnt-induced EMT. TGF- $\beta$ or Wnt3a-conditioned medium (CM, obtained from Wnt3a-secreting L cells) induced EMT and E-cadherin downregulation (Fig. 2A-F). TGF- $\beta$ and Wnt3a also increased expression of Dlx-2 and Snail (Fig. 2B, $\mathrm{C}, \mathrm{E}$ and $\mathrm{F}$ ). Note that TGF- $\beta$ increased Snail expression at both mRNA and protein levels, whereas Wnt induced Snail at the level of protein but not mRNA (Fig. 2B, C, E and F). In the Wnt signaling, Axin2 is one of the Wnt target genes and regulates EMT by acting as a chaperone for nuclear export of GSK $3 \beta$ that is the dominant kinase responsible for Snail protein turnover and activity, in human breast cancer cells, thereby increasing Snail protein stability in the nucleus (30). Thus, in 
A
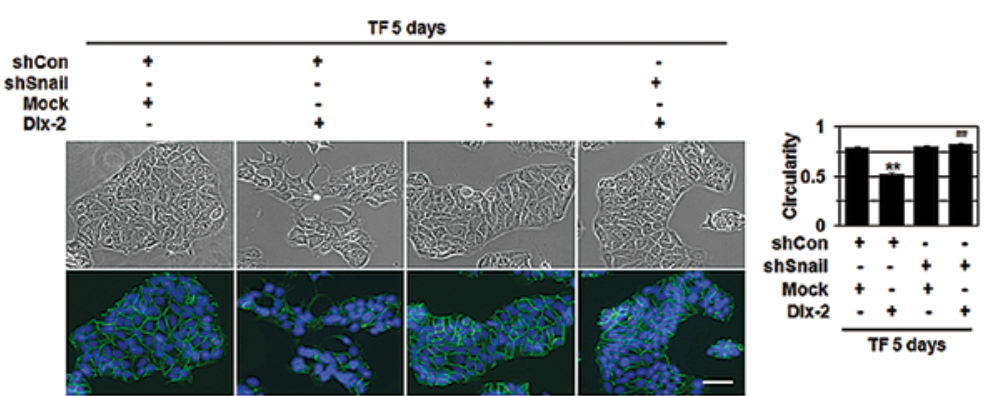

B

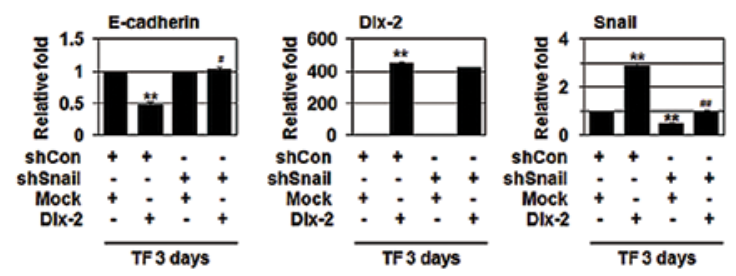

C
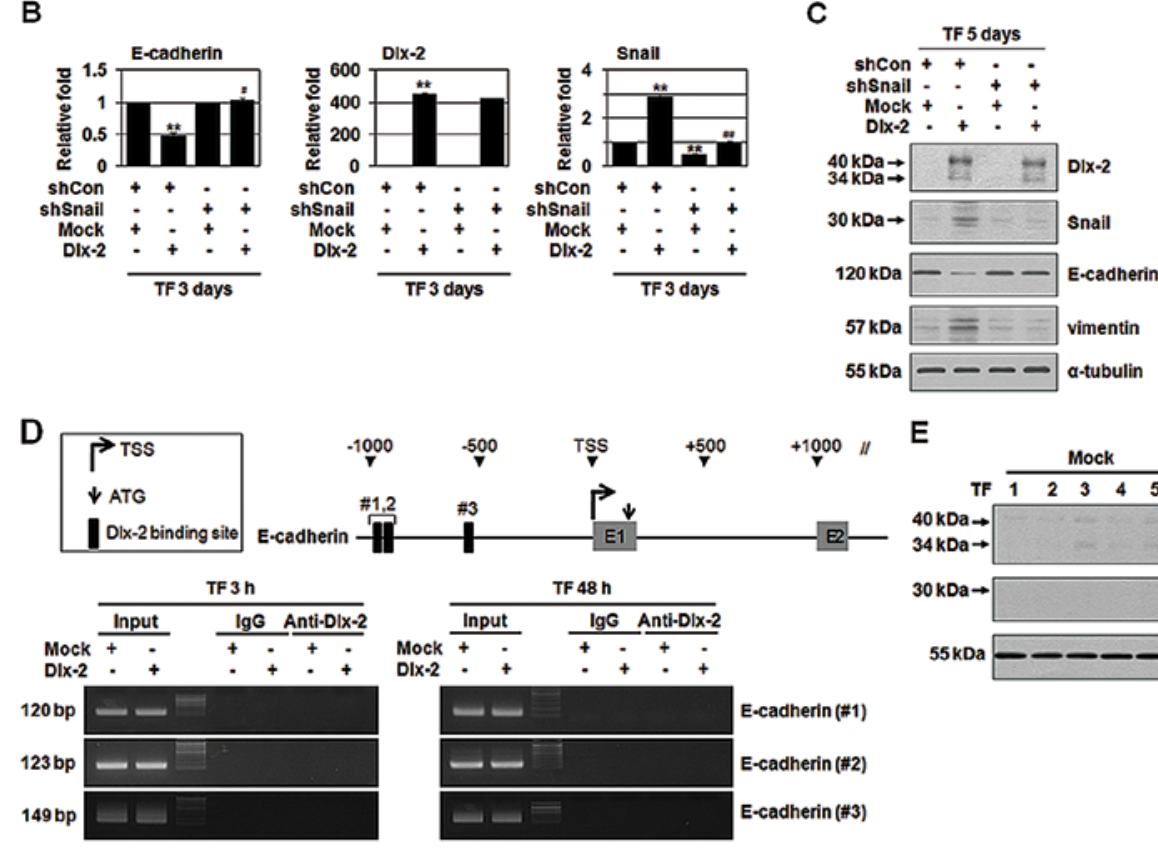

E

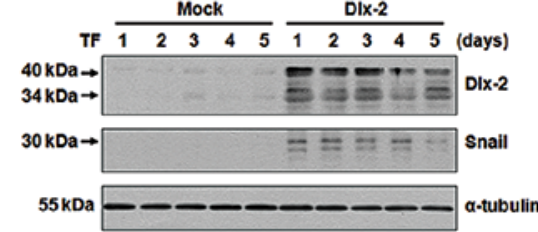

$F$
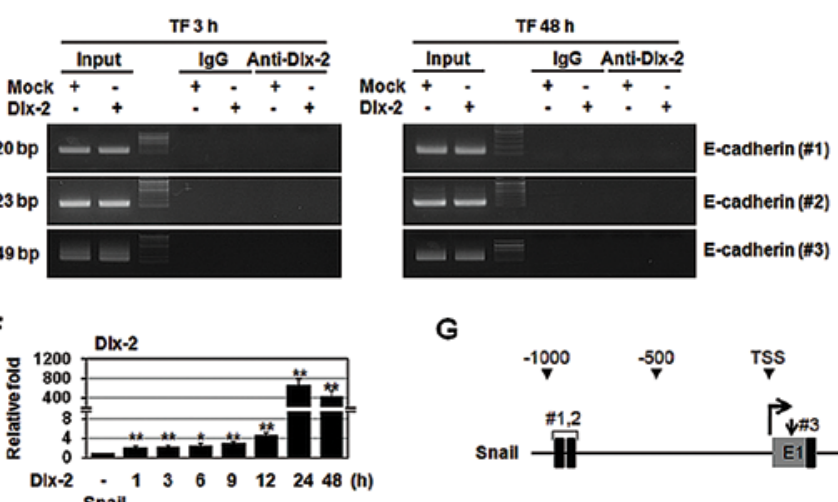

G

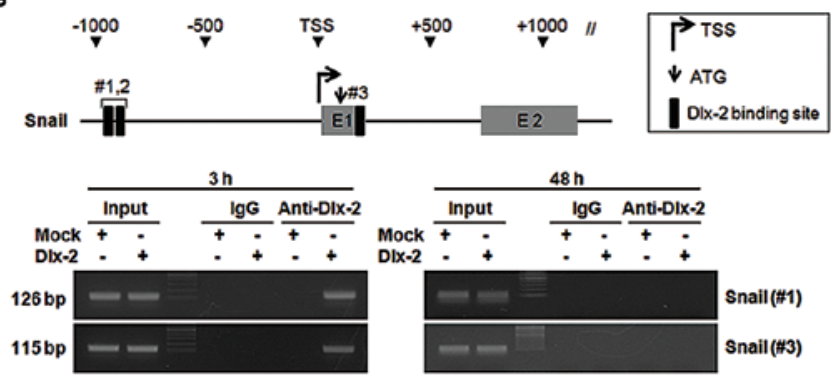

H
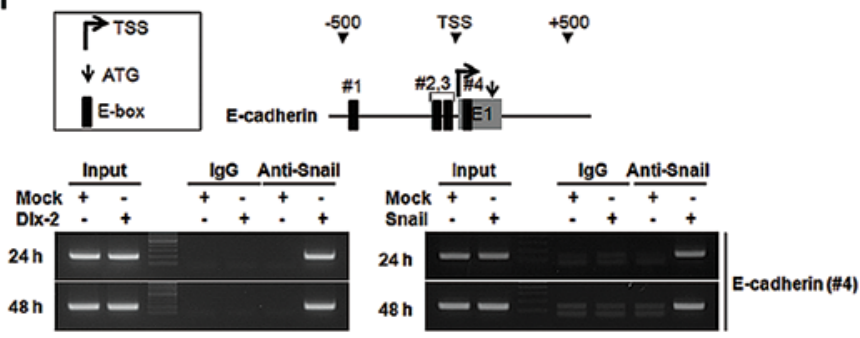

Figure 1. Dlx-2 induces EMT via Snail activation. (A-C) MCF-7 cells co-transfected with Dlx-2 and shSnail were analyzed by phase-contrast and fluorescence microscopy for cell morphology and E-cadherin expression (fluorescence in green; left) and circularity (right; A). The borders were drawn along the cell edges for quantification of circularity. The results (120-202 cells in each group) are mean \pm SE. The cells were also analyzed by qRT-PCR (B) and immunoblotting (C) using the indicated primers and antibodies. ${ }^{* *} \mathrm{P}<0.01$ versus mock, ${ }^{~} \mathrm{P}<0.05 ;{ }^{\# /} \mathrm{P}<0.01$ versus Dlx-2. (D) A schematic diagram of the human E-cadherin proximal promoter region is shown in the upper panel. MCF-7 cells were transfected with Dlx-2. ChIP assays were performed using IgG or anti-Dlx-2 antibodies and ChIP-enriched DNA was analyzed by PCR using primers complementary to the Dlx-2 binding region (lower panel). (E and F) MCF-7 cells transfected with Dlx-2 were analyzed by immunoblotting (E) and qRT-PCR (F) for Dlx-2 and Snail expression. ${ }^{*} \mathrm{P}<0.05 ;{ }^{* * *} \mathrm{P}<0.01$ versus mock. (G) A schematic diagram of the human Snail proximal promoter region is shown in upper panel. MCF-7 cells were transfected with Dlx-2 for the indicated times. ChIP assays were performed using IgG or anti-Dlx-2 antibodies and ChIP-enriched DNA was analyzed by PCR using primers complementary to the Dlx-2 binding region (lower panel) (H) A schematic diagram of the human E-cadherin proximal promoter region is shown in the upper panel. MCF-7 cells were transfected with Dlx-2 or Snail. ChIP assays were performed using IgG or anti-Snail and ChIP-enriched DNA was analyzed by PCR using primers complementary to the Snail binding region (E-box; lower panel). All error bars represent SE. The scale bars represent $100 \mu \mathrm{m}$. 
A
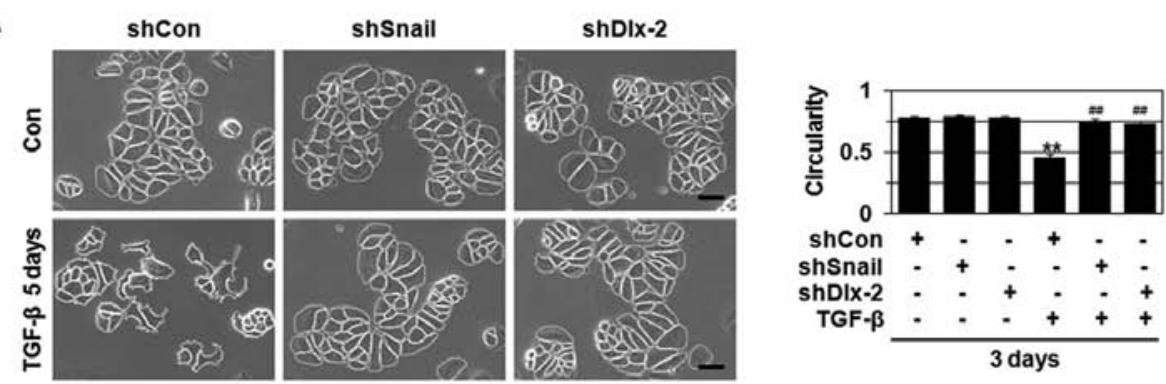

B
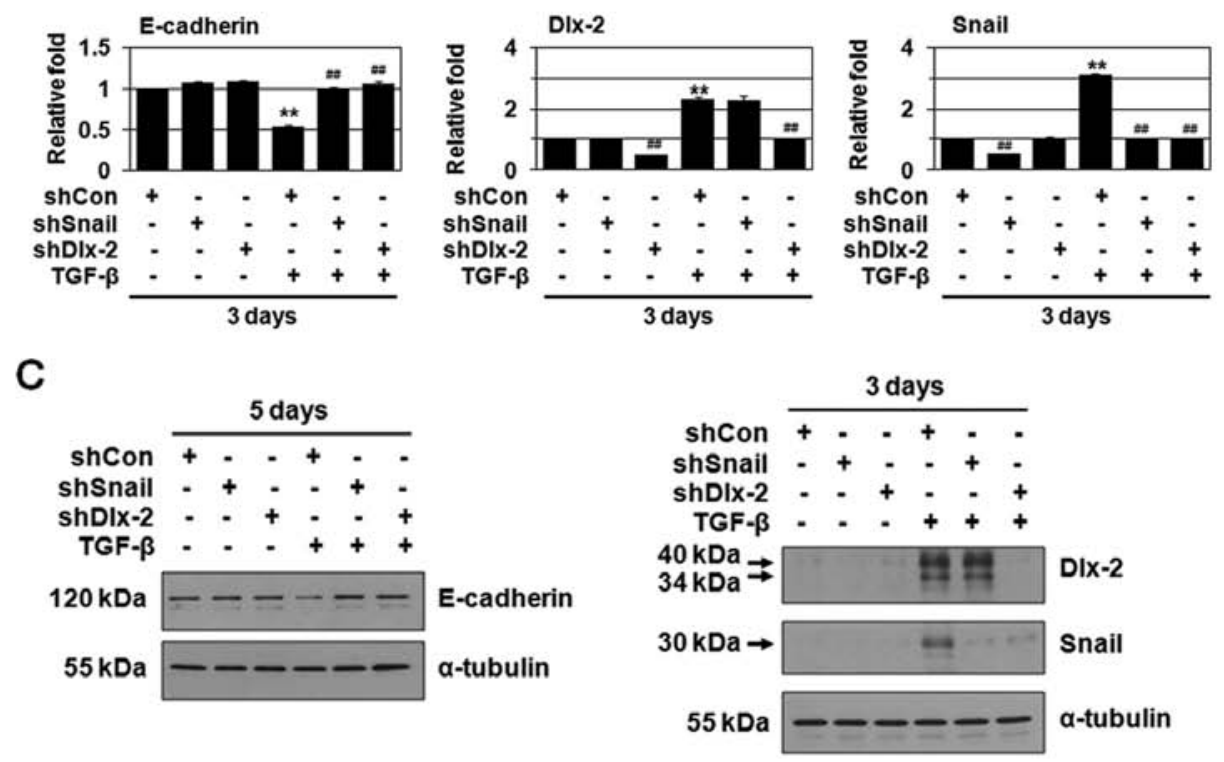

D
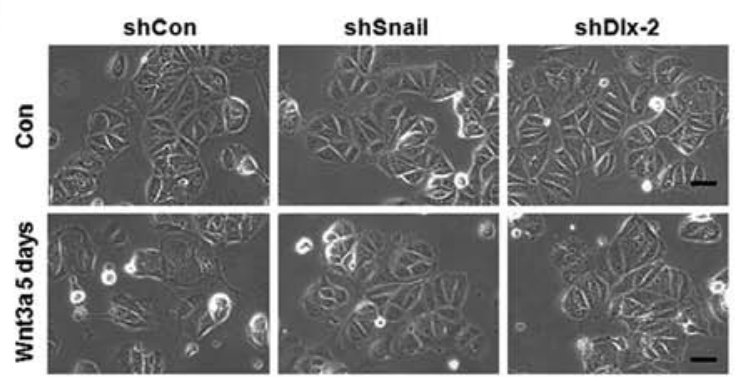

Figure 2. The Dlx-2/Snail cascade is implicated in TGF- $\beta$ - and Wnt3a-induced EMT. (A-F) MCF-7 cells were transfected with shDlx-2 or shSnail and then treated with TGF- $\beta$ (A-C) or Wnt3a CM (D-F). The cells were analyzed by phase-contrast microscopy for cell morphology (A and D). The borders were drawn along the cell edges for quantification of circularity (A).

Wnt signaling, Dlx-2 may be involved in GSK3 $\beta$-mediated Snail protein turnover; although it remained to be elucidated. shDlx-2 suppressed Snail expression, whereas shSnail had no effect on Dlx-2 expression (Fig. 2B, C, E and F), indicating that Dlx-2 acts upstream of Snail. shDlx-2 or shSnail appeared to block TGF- $\beta$ - and Wnt3a-induced EMT and E-cadherin downregulation (Fig. 2A-F).

TGF- $\beta$ induces EMT through activation of Smad signaling pathways (8). Smad2/3/4 shRNA suppressed TGF- $\beta$-induced EMT and E-cadherin downregulation (Fig. 2G) as well as Dlx-2 and Snail expression (Fig. 2G and H). Wnt induces EMT via canonical pathways, which includes $\beta$-catenin, TCF4 and Axin1/2. shRNA for $\beta$-catenin, TCF4 and Axin1/2 suppressed Wnt3a-induced EMT/E-cadherin downregulation (Fig. 2I) as well as Dlx-2 (but not Snail) expression (Fig. 2I and J). These results supported that the Dlx-2/Snail cascade is implicated in TGF- $\beta$ - and Wnt3a-induced EMT.

We further examined the effects of shDlx-2 and shSnail on the EMT in HCT116 and MDCK cells. shDlx- 2 and shSnail suppressed Wnt3a-induced EMT and E-cadherin downregulation in HCT116 cells (Fig. 2K and L). Similar inhibitory effects of shDlx-2 and shSnail on TGF- $\beta$-induced EMT were observed in MDCK cells. shDlx- 2 and shSnail prevented TGF- $\beta$-induced EMT and E-cadherin downregulation (Fig. 2M and N).

Dlx-2/Snail signaling is involved in TGF- $\beta$ - and Wnt3ainduced glycolytic switch and mitochondrial repression. Wnt3a/Snail cascade has been shown to induce glycolytic 
E
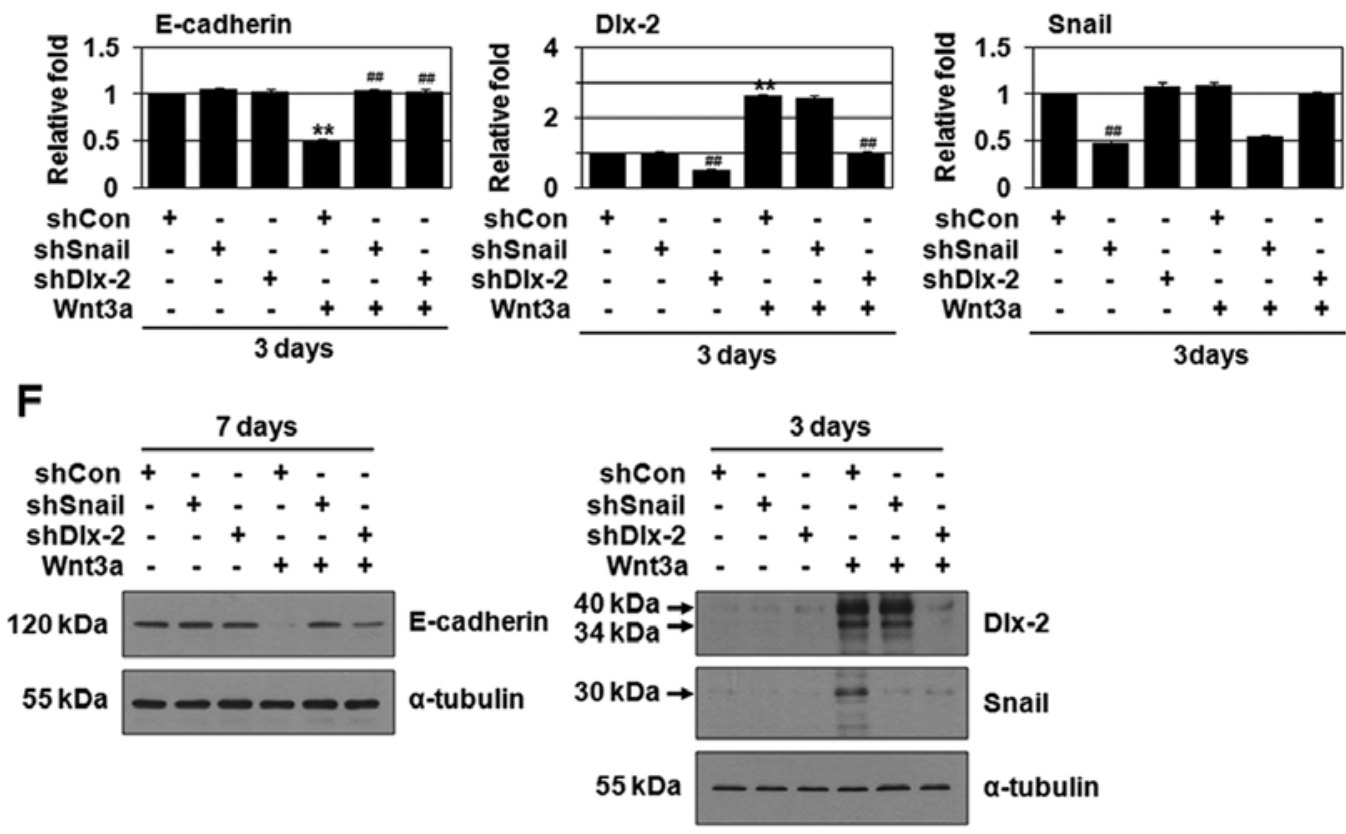

G
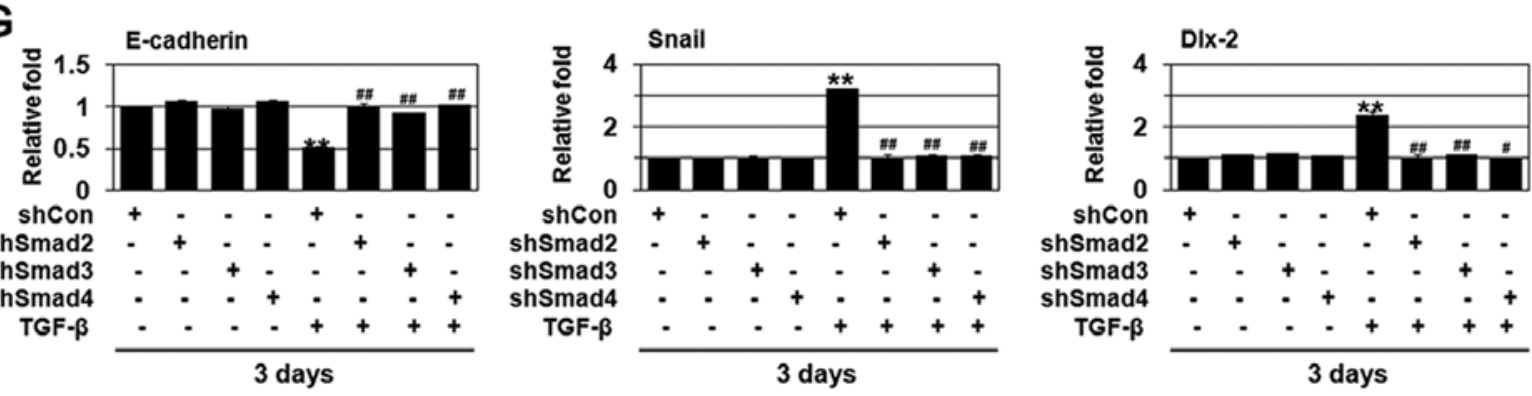

H

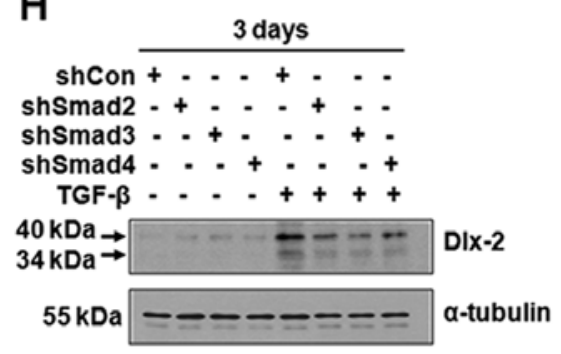

I
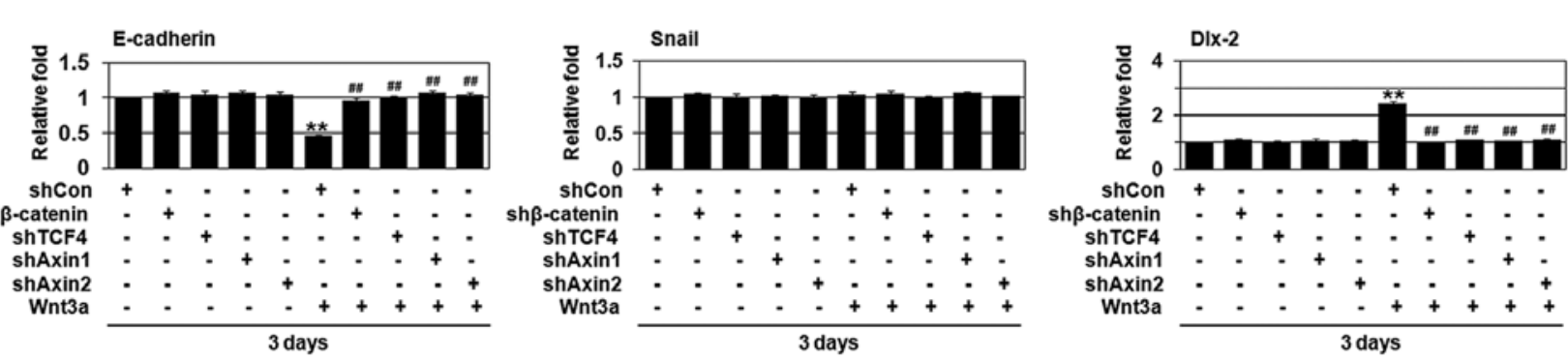

$\mathbf{J}$

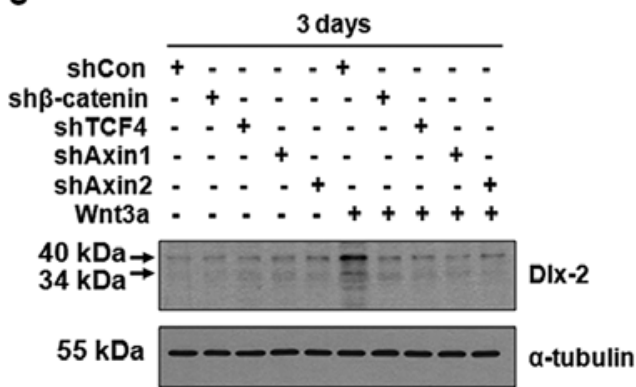

Figure 2. Continued. The results (42-84 cells in each group) are mean \pm SE The cells were also analyzed by qRT-PCR (B and E) and immunoblotting $(\mathrm{C}$ and $\mathrm{F})$ for $\mathrm{E}$-cadherin, Dlx-2 and Snail expression. ${ }^{* *} \mathrm{P}<0.01$ versus untreated, ${ }^{\# \#} \mathrm{P}<0.01$ versus shCon. (G and $\mathrm{H}$ ) MCF-7 cells transfected with Smad 2/3/4 shRNA and then treated with TGF- $\beta$ were analyzed qRT-PCR (G) and immunoblotting $(\mathrm{H})$ using the indicated primers and antibodies. ${ }^{* *} \mathrm{P}<0.01$ versus untreated, ${ }^{\#} \mathrm{P}<0.05 ;{ }^{\# \#} \mathrm{P}<0.01$ versus shCon. (I and J) MCF-7 cells transfected with shRNA for $\beta$-catenin, TCF4 and Axin1/2 and then treated with Wnt3a CM were analyzed by qRT-PCR (I) and immunoblotting (J) using the indicated primers and antibodies. ${ }^{* *} \mathrm{P}<0.01$ versus untreated, ${ }^{\# \#} \mathrm{P}<0.01$ versus shCon. 


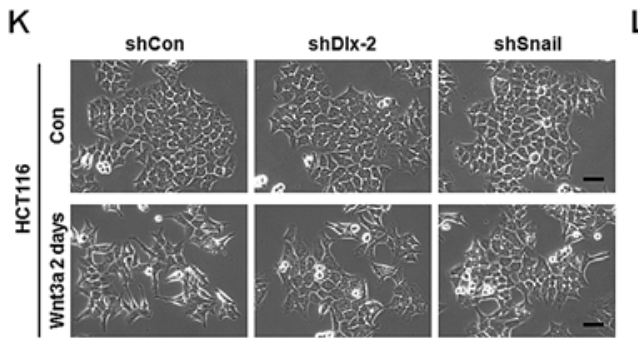

L
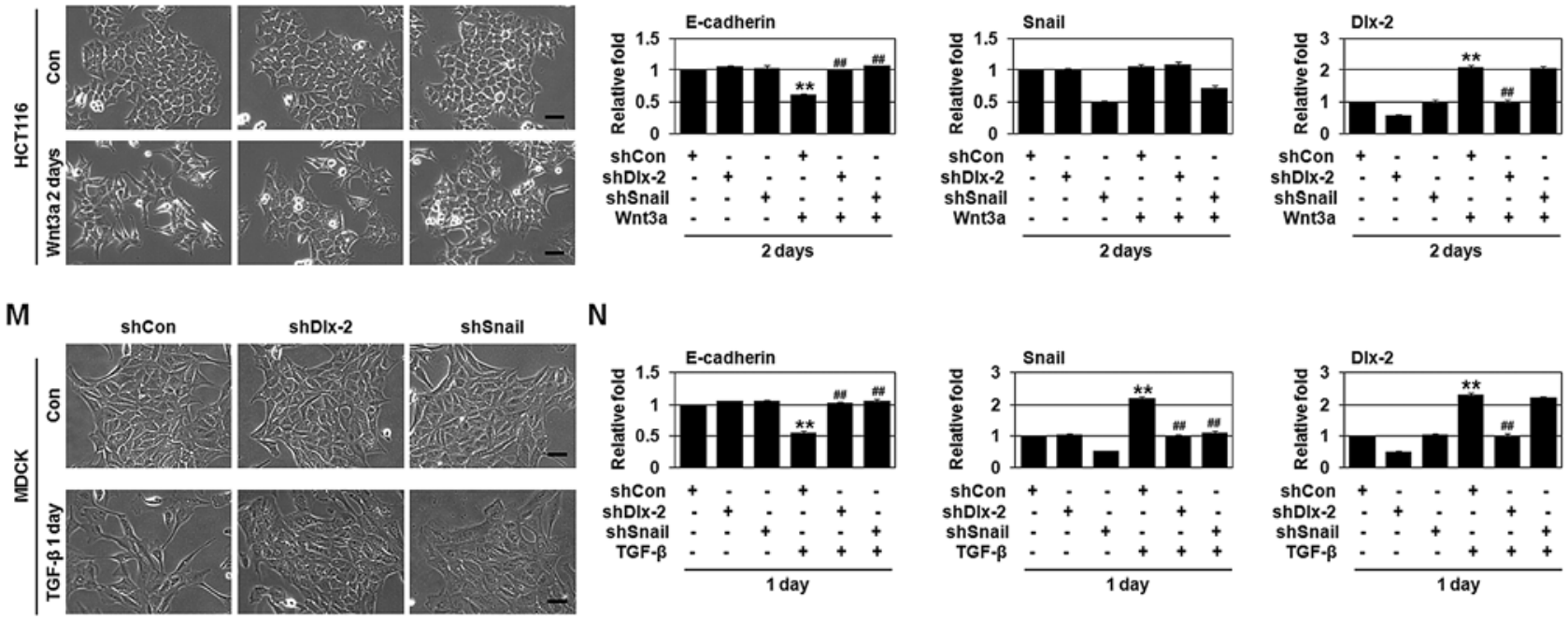

N
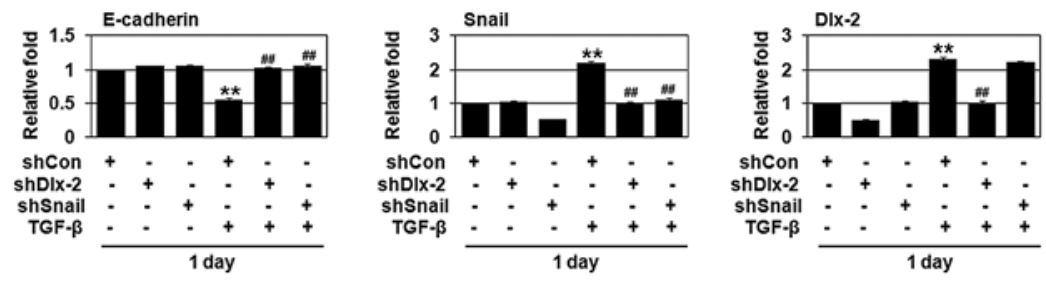

Figure 2. Continued. (K and L) HCT116 cells transfected with shDlx-2 or shSnail and then treated with Wnt3a CM were analyzed by phase-contrast for cell morphology $(\mathrm{K})$. The cells were also analyzed by qRT-PCR using the indicated primers $(\mathrm{L})$. ${ }^{* * *} \mathrm{P}<0.01$ versus untreated, ${ }^{\# \#} \mathrm{P}<0.01$ versus shCon. (M and $\mathrm{N}$ ) MDCK cells transfected with shDlx-2 or shSnail and then treated with TGF- $\beta$ were analyzed by phase-contrast for cell morphology (M). The cells were also analyzed by qRT-PCR using the indicated primers $(\mathrm{N}){ }^{* * *} \mathrm{P}<0.01$ versus untreated, ${ }^{\# \#} \mathrm{P}<0.01$ versus shCon. All error bars represent SE. Scale bars represent $100 \mu \mathrm{m}$.

Table IV. Regulation of COX subunits and assembly factors by Dlx-2 and TGF- $\beta$.

\begin{tabular}{llc}
\hline Genes & $\begin{array}{c}\text { Dlx-2 }(\mathrm{n}=5-13) \\
48 \mathrm{~h}\end{array}$ & $\begin{array}{c}\text { TGF- } \beta(\mathrm{n}=5-7) \\
48 \mathrm{~h}\end{array}$ \\
\hline E-cadherin & $0.697^{\mathrm{a}}$ & $0.571^{\mathrm{a}}$ \\
COX subunits & & \\
COXIV & $0.697^{\mathrm{a}}$ & $0.571^{\mathrm{a}}$ \\
COXVa & 1.044 & 1.152 \\
COXVb & 1.079 & 1.102 \\
COXVIa & 1.029 & 1.167 \\
COXVIb & 0.992 & 2.371 \\
COXVIc & 0.959 & 0.953 \\
COXVIIa & $0.778^{\mathrm{a}}$ & $0.380^{\mathrm{a}}$ \\
COXVIIb & 0.900 & $0.636^{\mathrm{a}}$ \\
COXVIIc & 1.031 & 0.920 \\
COXVIII & 1.016 & 1.055 \\
Assembly factors & & \\
COX10 & 1.090 & 0.905 \\
COX11 & 0.993 & 1.125 \\
COX15 & 0.927 & $0.680^{\mathrm{a}}$ \\
COX17 & 0.986 & 1.305 \\
COX18 & 1.080 & 1.156 \\
COX19 & 1.150 & 0.928 \\
LRPPRC & $0.679^{\mathrm{a}}$ & 0.994 \\
SURF1 & 1.072 & 1.049 \\
SCO1 & 1.078 & 1.152 \\
SCO2 & 1.034 & \\
\hline & & \\
\hline
\end{tabular}

Dlx, distal-less; COX, cytochrome $c$ oxidase; LRPPRC, leucine-rich pentatricopeptide repeat-containing protein; SCO, synthesis of cytochrome $c$ oxidase. MCF-7 cells were transfected with Dlx-2 or treated with TGF- $\beta$. The cells were analyzed by qRT-PCR. Data are mean of triplicate samples per condition of $>3$ independent experiments. ${ }^{\text {a }} \mathrm{P}<0.01$ versus control (mock or untreated). switch and mitochondrial repression (9). Therefore, we examined whether Dlx-2 is involved in the Snail-induced glycolytic switch. Dlx-2 overexpression significantly increased Glc consumption and Lac production (Fig. 3A). In addition, Dlx-2 overexpression decreased $\mathrm{O}_{2}$ consumption (Fig. 3A). ATP levels were similar in both control and Dlx-2 transfected cells (data not shown). By measuring oxygen consumption and Lac production, we estimated the relative contributions of glycolysis and aerobic respiration in total ATP production. Dlx-2 increased the ratio of ATP produced by glycolysis versus ATP produced by aerobic respiration (Fig. 3A), indicating that Dlx-2 induces glycolytic switch. Dlx-2-induced glycolytic switch and mitochondrial repression were prevented by shSnail (Fig. 3A), indicating that Dlx-2 induces glycolytic switch/mitochondrial repression via Snail.

Then, we examined if TGF- $\beta$ and Wnt3a induce glycolytic switch/mitochondrial repression via the Dlx-2/Snail cascade. TGF- $\beta$ and Wnt3a induced Glc consumption and Lac production (Fig. 3B and C). In addition, TGF- $\beta$ and Wnt3a reduced $\mathrm{O}_{2}$ consumption (Fig. $3 \mathrm{~B}$ and $\mathrm{C}$ ). Although total ATP concentrations remained the same in all cells, TGF- $\beta$ and Wnt 3 a increased the ratio of ATP produced by glycolysis versus ATP produced by aerobic respiration (Fig. 3B and C), indicating that TGF- $\beta$ and Wnt3a induce glycolytic switch. In addition, shDlx-2 or shSnail decreased TGF- $\beta$ - and Wnt3a-induced increase of Glc consumption and Lac production and impairment of $\mathrm{O}_{2}$ consumption (Fig. 3B and $\mathrm{C}$ ), indicating that the Dlx-2-Snail axis is involved in TGF- $\beta$ - and Wnt3a-induced glycolytic switch and mitochondrial repression.

Dlx-2/Snail signaling is involved in TGF- $\beta /$ Wnt-induced $C O X$ inhibition. Changes in the activity of COX, the terminal enzyme of the mitochondrial respiratory chain, are closely associated with decreased mitochondrial respiratory activity. Therefore, we examined the effects of Dlx-2 on COX activity. 
A

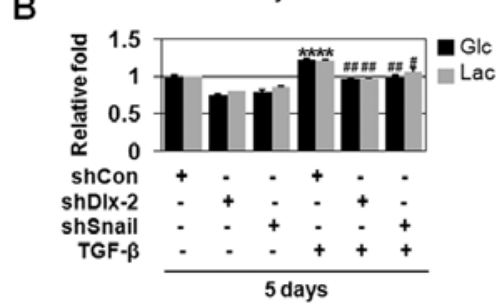

C

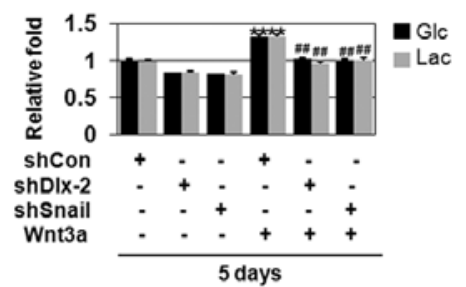

D

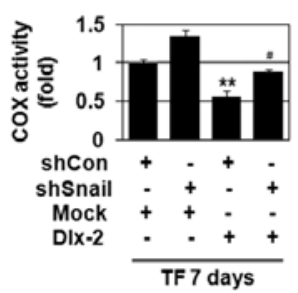

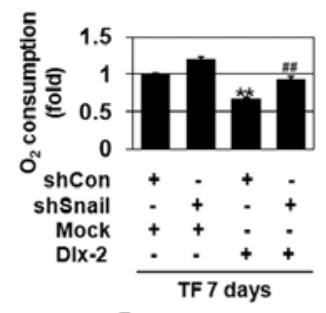
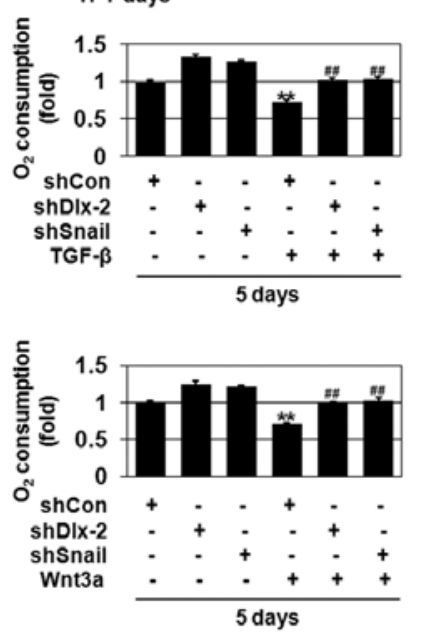

$\mathrm{F}$

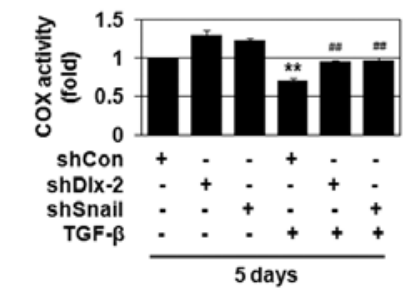

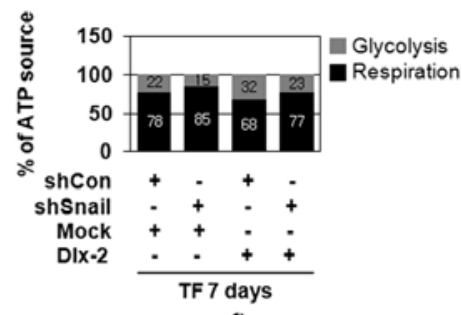
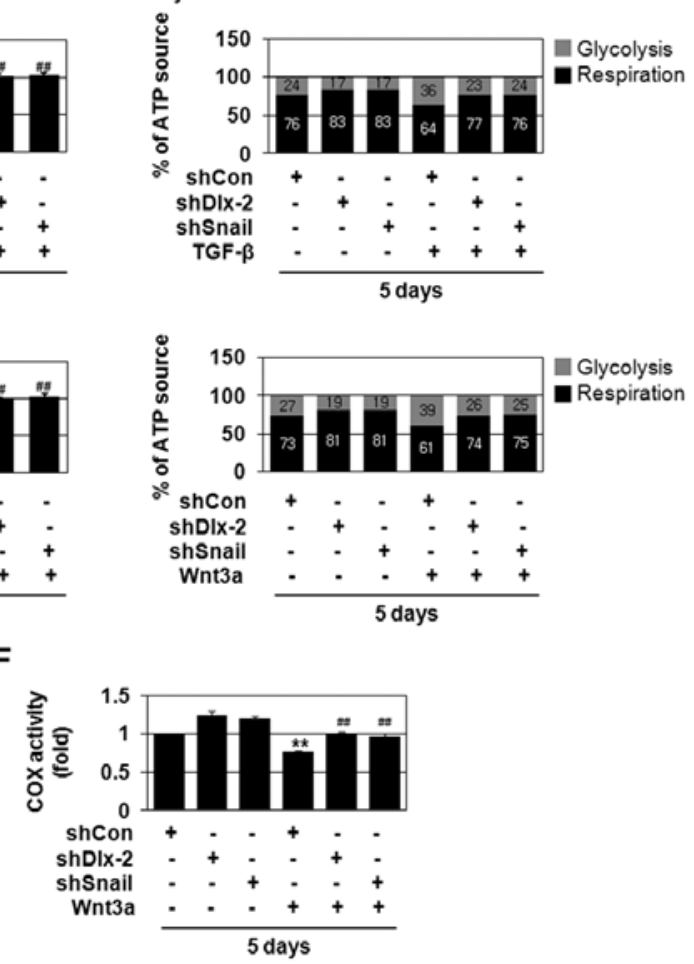

Figure 3. The Dlx-2/Snail cascade is implicated in TGF- $\beta$ - and Wnt3a-induced glycolytic switch, mitochondrial repression and COX inhibition. (A) MCF-7 cells were co-transfected with Dlx-2 and shSnail. The cells were analyzed for glucose (Glc) consumption, lactate (Lac) production, mitochondrial respiration and percentage (\%) of ATP source. ${ }^{* *} \mathrm{P}<0.01$ versus mock, ${ }^{\# \#} \mathrm{P}<0.01$ versus Dlx-2. (B and C) MCF-7 cells were transfected with shDlx-2 or shSnail and then treated with TGF- $\beta$ (B) or Wnt3a CM (C). The cells were analyzed by Glc consumption, Lac production, mitochondrial respiration and percentage (\%) of ATP source. ${ }^{* *} \mathrm{P}<0.01$ versus untreated, ${ }^{\#} \mathrm{P}<0.05 ;{ }^{\# \#} \mathrm{P}<0.01$ versus shCon. The amount of ATP produced by aerobic respiration (black bars) and glycolysis (gray bars) was calculated by measuring oxygen consumption and Lac production in the cells (right panels in A-C). (D) COX activity was measured in MCF-7 cells co-transfected with Dlx-2 and shSnail. ${ }^{* *} \mathrm{P}<0.01$ versus control (mock and shCon), ${ }^{\#} \mathrm{P}<0.05$ versus Dlx-2. (E and F) MCF-7 cells transfected with shDlx-2 or shSnail were treated with TGF- $\beta$ (E) or Wnt3a CM (F), and COX activity was measured. ${ }^{* *} \mathrm{P}<0.01$ versus untreated, ${ }^{* \#} \mathrm{P}<0.01$ versus shCon. All error bars represent SE.

Dlx-2 overexpression reduced COX enzymatic activity (Fig. 3D). Dlx-2-induced COX inhibition was prevented by shSnail (Fig. 3D), indicating that Dlx-2 induces COX inhibition via Snail activation.

We also found that TGF- $\beta$ and Wnt3a reduce COX activity (Fig. 3E and F). We examined if Dlx-2-Snail axis is implicated in TGF- $\beta$ - and Wnt3a-induced COX inhibition. shDlx-2 or shSnail decreased TGF- $\beta$ - and Wnt3a-induced impairment of COX activity (Fig. 3E and F), indicating that the Dlx-2-Snail axis is involved in TGF- $\beta$ - and Wnt3a-induced mitochondrial repression.

Dlx-2/Snail signaling is implicated in TGF- $\beta /$ Wnt-induced downregulation of multiple COX subunits and assembly factors. Eukaryotic COX is composed of 13 different subunits and its assembly is regulated by a sequential action of several nucleus-encoded assembly factors. We examined the effects of Dlx-2 and Snail on the gene expression of COX subunits and assembly factors using real-time PCR (Table IV). Dlx-2 downregulated the expression of COXVIc and COX19 (Table IV and Fig. 4A-C). Snail has been shown to decrease mRNA levels of COXVIc, COXVIIa and COXVIIc (9). Note that Snail-mediated COXVIIa and COXVIIc repression was not observed in Dlx-2 expressing cells. shSnail suppressed Dlx-2-induced reduction in the levels of COXVIc, but not COX19 (Fig. 4A and C), suggesting that Snail is implicated in Dlx-2-mediated COXVIc gene repression, but not in COX19 gene repression. Dlx-2 overexpression enhanced Snail binding to the COXVIc promoter, but not COX19 promoter (Fig. 4D), confirming that COXVIc, but not COX19, is regulated by a Snail-dependent mechanism. As expected, Dlx-2 also did not bind to the COX19 promoter (Fig. 4E).

We examined the effects of TGF- $\beta$ and Wnt on the gene expression of COX subunits and assembly factors using real-time PCR. TGF- $\beta$ decreased mRNA levels of COXVIc, COXVIIa and COX11 (Table IV and Fig. 4F). Snail-mediated 
A
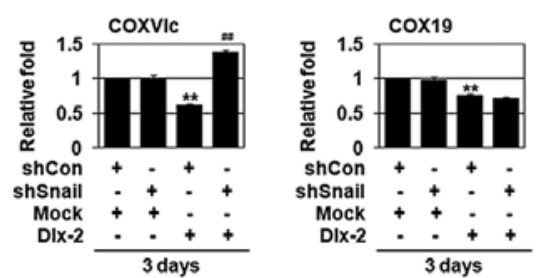

D
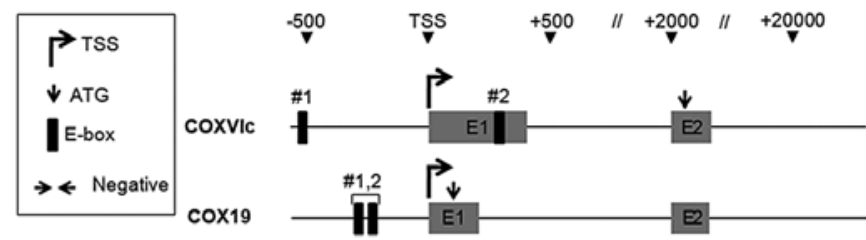

coxvilla
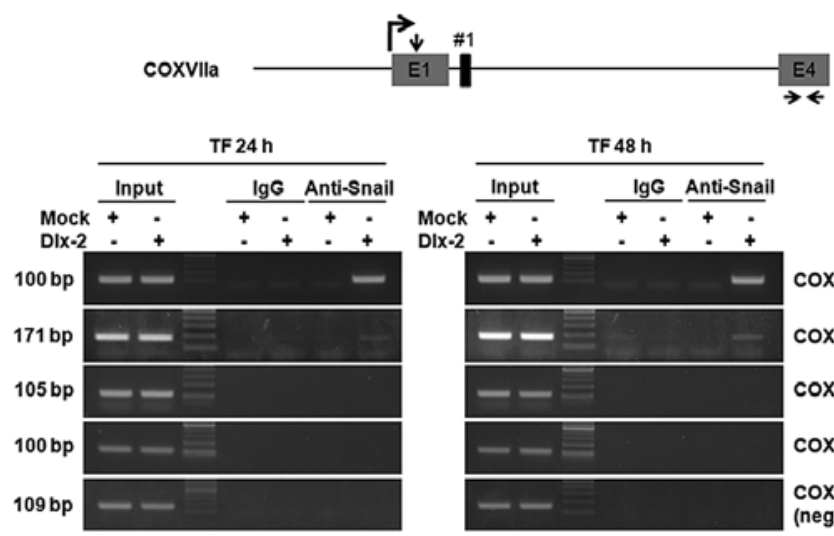

B

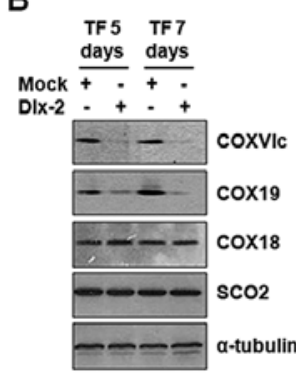

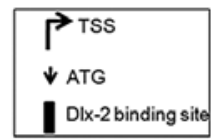
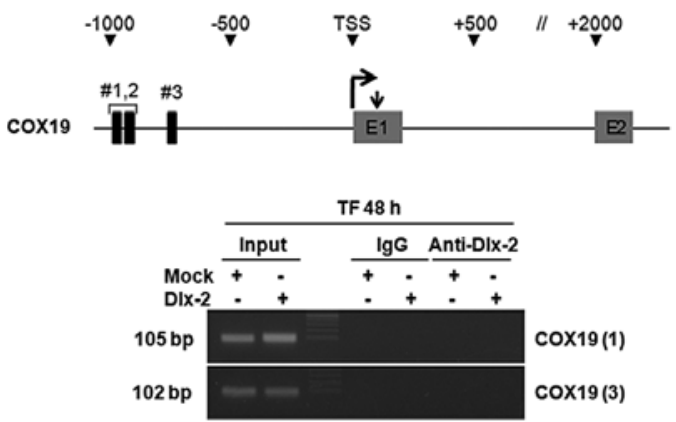

Figure 4. Regulation of COX subunits and assembly factors by Dlx-2 and TGF- $\beta$. (A) MCF-7 cells were co-transfected with Dlx-2 and shSnail and analyzed by qRT-PCR for COXVIc and COX19 expresssion. ${ }^{* *} \mathrm{P}<0.01$ versus control (mock and shCon), ${ }^{\# \#} \mathrm{P}<0.01$ versus Dlx-2. (B and C) MCF-7 cells were transfected with Dlx-2 (B) or co-transfected with Dlx-2 and shSnail (C) and analyzed by immunoblotting with the indicated antibodies. (D) A schematic diagram of the human COXVIc, COXVIIa and COX19 promoter regions is shown in the upper panel. MCF-7 cells were transfected with Dlx-2 for 24 and $48 \mathrm{~h}$. ChIP assays were performed using IgG or anti-Snail antibodies and ChIP-enriched DNA was analyzed by PCR using primers complementary to the Snail binding region (lower panel). The primers for COXVIIa exonic region were used as a negative control. (E) A schematic diagram of the human COX19 proximal promoter region is shown in the upper panel. MCF-7 cells were transfected with Dlx-2 for $48 \mathrm{~h}$. ChIP assays were performed using IgG or anti-Dlx-2 antibodies and ChIP-enriched DNA was analyzed by PCR using primers complementary to the Dlx-2 binding region (lower panel).

COXVIIc repression was not observed in TGF- $\beta$-treated cells by unknown mechanism. shSnail suppressed TGF- $\beta$-induced reduction in the levels of COXVIc and COXVIIa, but not COX11 (Fig. 4F). shDlx-2 suppressed TGF- $\beta$-induced reduction in the levels of COXVIc (Fig. 4G). In case of Wnt3a, it decreased mRNA levels of COXVIc, COXVIIa and COXVIIc (Fig. 4H) (9). shSnail suppressed Wnt3a-induced reduction in the levels of COXVIc, COXVIIa and COXVIIc (Fig. 4H). shDlx-2 also suppressed Wnt3a-induced reduction in the levels of COXVIc (Fig. 4I).

COXVIc was a common target of TGF- $\beta$, Wnt, Dlx-2 and Snail. Because TGF- $\beta$ - and Wnt-induced COX inhibition was suppressed by shDlx-2, COXVIc levels seem to be more important. Thus, TGF- $\beta$ - and Wnt-induced COX inhibition is thought to be mediated by COXVIc inhibition by the Dlx-2/ Snail-mediated pathway.

We examined the effects of shCOXVIc on mitochondrial respiration and COX activity. Without affecting the cell morphology (Fig. 4J), shCOXVIc inhibited mitochondrial respiration and COX activity (Fig. 4K).
The expression of Dlx-2, Snail and COXVIc in human tumors. To further examine the physiological relevance of Dlx-2/ Snail/COXVIc cascade, we analyzed human tumor samples. We examined the expression of Dlx-2, Snail and COXVIc by qRT-PCR using RNAs extracted from paired biopsy of breast cancer and the corresponding normal tissues. Dlx-2 and Snail expression were higher and COXVIc expression was lower irrespective of the stage in breast cancer tissues compared with matched normal tissues (Fig. 4L). We also examined the expression of Dlx-2 and Snail protein using immunoblotting. Dlx-2 and Snail expression were higher in breast cancer tissues than in matched non-tumorigenic tissues (Fig. 4L). These results further support an important role of Dlx-2 and Snail in tumor development.

In this study, we show novel functions of Dlx-2 that contribute to tumor development and progression; to induce EMT and glycolytic switch. Dlx-2 induced EMT and glycolytic switch via Snail activation. The Dlx-2/Snail cascade was involved in TGF- $\beta /$ Wnt-induced EMT and glycolytic switch. Furthermore, we found that TGF- $\beta /$ Wnt suppressed COX in 
F

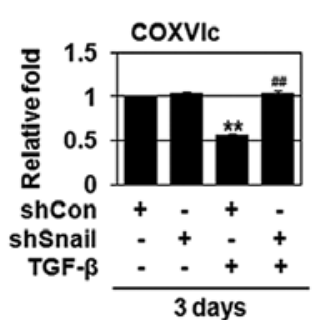

$\mathrm{H}$

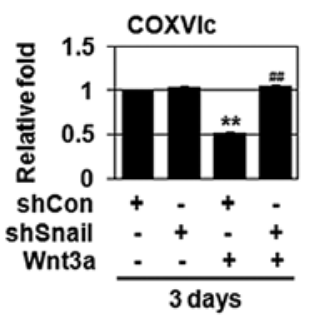

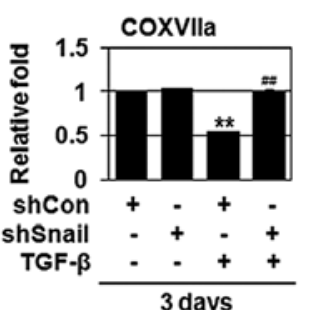

3 days

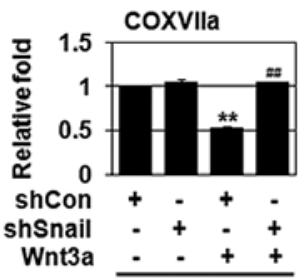

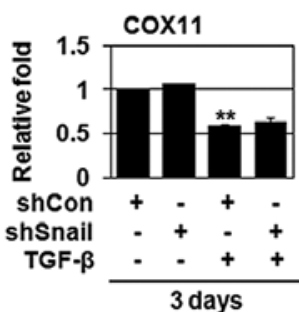

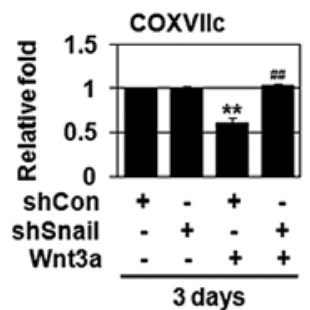

G

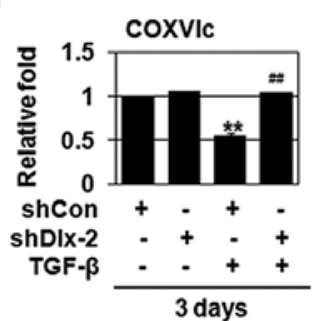

I

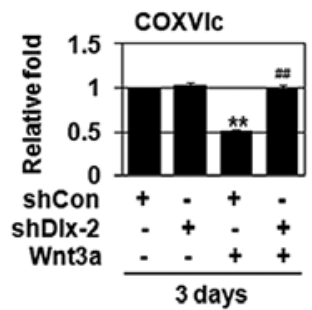

J

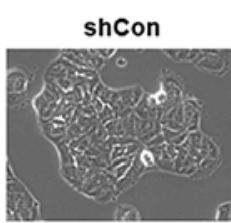

shcoxvic

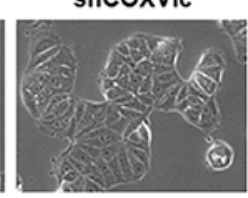

K
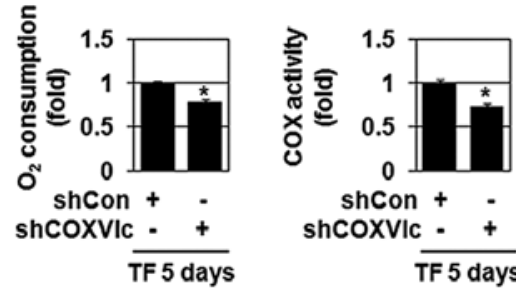

L

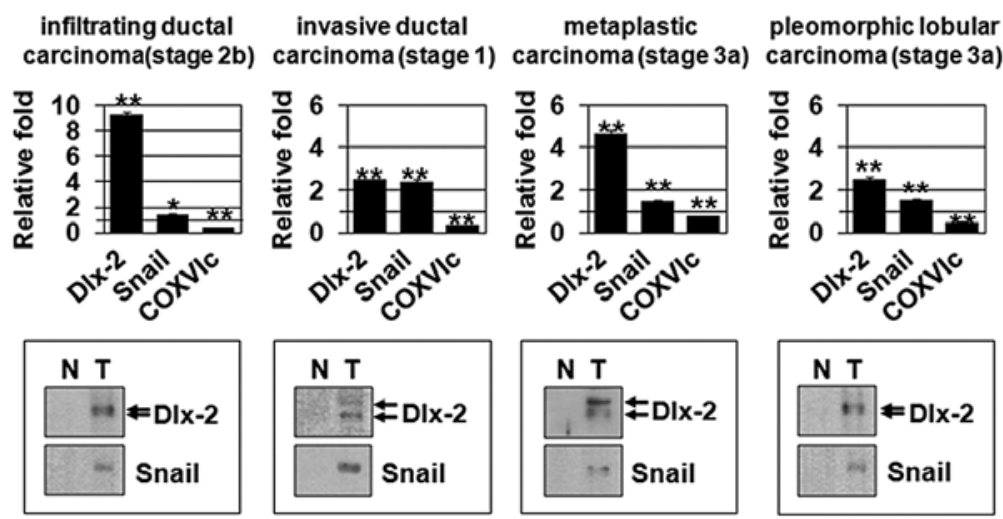

Figure 4. Continued. (F-I) MCF-7 cells transfected with shSnail (F and H) or shDlx-2 (G and I) were treated with TGF- $\beta$ (F and G) or Wnt3a CM (H and I), and analyzed by qRT-PCR using the indicated primers. ${ }^{* *} \mathrm{P}<0.01$ versus untreated, ${ }^{\# \#)} \mathrm{P}<0.01$ versus shCon. $(\mathrm{J}$ and $\mathrm{K}) \mathrm{MCF}-7$ cells were transfected with shCOXVIc. The cells were analyzed by phase-contrast microscopy for cell morphology $(\mathrm{J})$. The cells were analyzed for mitochondrial respiration and COX activity (K). ${ }^{*} \mathrm{P}<0.05$ versus shCon. (L) qRT-PCR data of Dlx-2, Snail and COXVIc, and immunoblotting of Dlx-2 and Snail in normal (N) and tumor (T) tissues of the indicated tumor types and histological stages (TNM classification) of breast cancer. ${ }^{*} \mathrm{P}<0.05 ;{ }^{* *} \mathrm{P}<0.01$ versus matched normal $(\mathrm{N})$ tissues. All error bars represent SE.

a Dlx-2/Snail-dependent manner. COXVIc downregulation appeared to play an important role in TGF- $\beta /$ Wnt-induced COX inhibition. Taken together, our findings suggest that Dlx-2 plays an important role in TGF- $\beta$ - and Wnt-induced tumor progression and aggressiveness.

\section{Acknowledgements}

This study was supported by the National Research Foundation of Korea (NRF) grant funded by the Korea government (MSIP) (nos. 2011-0011084, 2013M2B2A9A03050902 and 2012R1A1A2044246) and by a grant from the National R\&D
Program for Cancer Control, Ministry of Health and Welfare, Republic of Korea (1320040). We thank Drs. K.L. Jang, Y.H. Moon and D. S. Min for providing their qRT-PCR machines.

\section{References}

1. De Craene B and Berx G: Regulatory networks defining EMT during cancer initiation and progression. Nat Rev Cancer 13: 97-110, 2013

2. Nieto MA: The snail superfamily of zinc-finger transcription factors. Nat Rev Mol Cell Biol 3: 155-166, 2002.

3. Puisieux A, Brabletz T and Caramel J: Oncogenic roles of EMT-inducing transcription factors. Nat Cell Biol 16: 488-494, 2014. 
4. Thiery JP and Sleeman JP: Complex networks orchestrate epithelial-mesenchymal transitions. Nat Rev Mol Cell Biol 7: 131-142, 2006

5. Zheng $\mathrm{H}$ and Kang Y: Multilayer control of the EMT master regulators. Oncogene 33: 1755-1763, 2014.

6. Liu YN, Lee WW, Wang CY, Chao TH, Chen Y and Chen JH: Regulatory mechanisms controlling human E-cadherin gene expression. Oncogene 24: 8277-8290, 2005.

7. Polyak K and Weinberg RA: Transitions between epithelial and mesenchymal states: acquisition of malignant and stem cell traits. Nat Rev Cancer 9: 265-273, 2009.

8. Thiery JP, Acloque H, Huang RY and Nieto MA: Epithelialmesenchymal transitions in development and disease. Cell 139: 871-890, 2009

9. Lee SY, Jeon HM, Ju MK, et al: Wnt/Snail signaling regulates cytochrome $c$ oxidase and glucose metabolism. Cancer Res 72 3607-3617, 2012.

10. Cairns RA, Harris IS and Mak TW: Regulation of cancer cell metabolism. Nat Rev Cancer 11: 85-95, 2011.

11. Dang CV: Links between metabolism and cancer. Genes Dev 26 877-890, 2012.

12. Hsu PP and Sabatini DM: Cancer cell metabolism: Warburg and beyond. Cell 134: 703-707, 2008

13. Vander Heiden MG, Cantley LC and Thompson CB: Understanding the Warburg effect: the metabolic requirements of cell proliferation. Science 324: 1029-1033, 2009.

14. Warburg O: On the origin of cancer cells. Science 123: 309-314, 1956.

15. Alirol E and Martinou JC: Mitochondria and cancer: is there a morphological connection? Oncogene 25: 4706-4716, 2006.

16. Brandon M, Baldi P and Wallace DC: Mitochondrial mutations in cancer. Oncogene 25: 4647-4662, 2006.

17. Kroemer G: Mitochondria in cancer. Oncogene 25: 4630-4632, 2006.

18. Gogvadze V, Orrenius S and Zhivotovsky B: Mitochondria in cancer cells: what is so special about them? Trends Cell Biol 18: 165-173, 2008.
19. Merlo GR, Zerega B, Paleari L, Trombino S, Mantero S and Levi G: Multiple functions of Dlx genes. Int J Dev Biol 44: 619-626, 2000.

20. Panganiban G and Rubenstein JL: Developmental functions of the Distal-less/Dlx homeobox genes. Development 129: 4371-4386, 2002

21. Lee SY, Jeon HM, Kim CH, et al: Homeobox gene Dlx-2 is implicated in metabolic stress-induced necrosis. Mol Cancer 10: 113, 2011.

22. Tang P, Huang H, Chang J, Zhao GF, Lu ML and Wang Y: Increased expression of DLX2 correlates with advanced stage of gastric adenocarcinoma. World J Gastroenterol 19: 2697-2703, 2013.

23. Yilmaz M, Maass D, Tiwari N, et al: Transcription factor Dlx2 protects from TGFbeta-induced cell-cycle arrest and apoptosis. EMBO J 30: 4489-4499, 2011.

24. Hussain SP, Hofseth LJ and Harris CC: Radical causes of cancer. Nat Rev Cancer 3: 276-285, 2003.

25. Weinberg F and Chandel NS: Reactive oxygen species-dependent signaling regulates cancer. Cell Mol Life Sci 66: 3663-3673, 2009.

26. Kim CH, Jeon HM, Lee SY, et al: Implication of snail in metabolic stress-induced necrosis. PLoS One 6: e18000, 2011.

27. Yoon YS, Lee JH, Hwang SC, Choi KS and Yoon G: TGF beta1 induces prolonged mitochondrial ROS generation through decreased complex IV activity with senescent arrest in Mv1Lu cells. Oncogene 24: 1895-1903, 2005.

28. Sariban-Sohraby S, Magrath IT and Balaban RS: Comparison of energy metabolism in human normal and neoplastic (Burkitt's lymphoma) lymphoid cells. Cancer Res 43: 4662-4664, 1983.

29. Batlle E, Sancho E, Franci C, et al: The transcription factor snail is a repressor of E-cadherin gene expression in epithelial tumour cells. Nat Cell Biol 2: 84-89, 2000.

30. Yook JI, Li XY, Ota I, et al: A Wnt-Axin2-GSK3beta cascade regulates Snaill activity in breast cancer cells. Nat Cell Biol 8: 1398-1406, 2006. 